Books, videos, cd-roms, dvds and any other relevant items submitted for a review in the BDJ should be addressed to:

Mike Grace, Editor, British Dental Journal, 64 Wimpole Street WIG 8YS

\section{Treatment Planning in Primary Dental Care}

\author{
A. Shearer and A. Mellor \\ Oxford: Oxford, 2003 \\ price $€ 24.95$, pp 115 \\ ISBN 0198508956
}

This book is beautifully written, appropriately illustrated, of a sensible length and is so logically and simply laid out that it is easy to read in one sitting. The breadth and depth of what is covered in the book is quite extraordinary, given that it is a relatively short text, but this is perhaps because of the succinct and direct prose style. This style of the book will make it particularly attractive to students. It has a sort of warm and welcoming tone - quite different from a normal text book which reminds the reader of a kind, helpful friendly tutor. That is probably because the authors, as well as being highly experienced and talented clinicians, both have a wealth of teaching experience and clearly know what works with undergraduates and what does not!

The first three chapters focus on the first part of a consultation with a patient. The principles underpinning treatment planning, communication with the patient and patient management are discussed. It is a joy to see subjects such as the importance of listening skills, and dental anxiety made central in a mainstream clinical text instead of, as is often the case, being banished to a footnote or even a specialist text. The next three chapters focus on diagnostic and decision making skills. Again, social, psychological and communication skills are put at the heart of the descriptions of how to care for a patient and this leads to a clear and logical pathway for treatment planning.

The next two chapters detail all the major pathologies and problems a dentist is likely to encounter. Clear guidance on what to do, on how to do it, and why it should be done, is given and it seems quite remarkable that so much information can be conveyed so efficiently and effectively.
The final chapter consists of treatment planning examples. All students and all dentists will enjoy these, sometimes quite challenging, patient examples. This chapter is the perfect end to a delightful book.

This book tells the student all the little things that most of us picked up after we had qualified. It illustrates theoretical and conceptual models of health, research tools, the evidence underpinning dentistry without ever losing its 'flow' or forgetting that its prime purpose is to educate, inform and help people become better dentists

E. Kay

\section{Masters of Functional Orthodontics}

\author{
A. Levrini and L. Favero (Eds) \\ Surrey: Quintessence, 2003 \\ price $€ 136, p p 416$ \\ ISBN 1850970769
}

This is an amazing book on how functional appliances have evolved, starting with Hippocrates (460-377 BC). Well known fathers of orthodontics and dento-facial orthopaedics are all mentioned in various detail. Even those with no interest in history will be fascinated to learn how various components such as chin cups, expansion plates and a variety of functional appliances have been developed and by whom. The first chapter describes all these in suitable detail right up to the present time.

The second chapter deals with concepts of functional therapy and it is a chapter well illustrated with portraits and sketches of various appliances and the masters who developed them. Each of the pioneers and ideas for functional treatment are described in just enough detail to keep any orthodontist interested. This theme is very much duplicated in subsequent chapters, leading overall to a marvellous compilation of the history of functional orthodontics. The book is not a critique; it is an historical account. Subjects are always more interesting if there is an historical background attached and I feel this is one of the most splendid books of dental history I have read.

I suspect there may be a limited market, probably restricted to orthodontists and maybe then only teaching institutions. It would be a text treasured on a personal basis, but I wonder if, with the pressures on postgraduates for publishing and reading, they may not find the time to fully grasp the enormity of the task undertaken by the authors when compiling this account.

I enjoyed reading this book and would like to see it available to orthodontists in any teaching institution.

\section{Medicine for Dentists - A Problem Based Approach}

\author{
S. Dimmitt \\ Crawley WA: University of Western Australia Press, \\ 2003 \\ price $\$ 39.39$ (AUD), pp158 \\ ISBN 1920694021
}

This is a fairly slim volume but none the less contains a wealth of useful information on medical conditions that any dental practitioner might commonly encounter.

The book is divided into 27 easy to read chapters which employ a problembased approach in dealing with various medical situations and conditions.

Another very commendable feature is that consistently throughout the common conditions are listed first rather than overloading the reader with rarities.

Some good quality clinical photographs are to be found towards the middle of the book but they do seem to be unrelated to the surrounding text.

The book contains seven appendices and a 44 page glossary. The appendices all contain useful information, particularly those relating to the 

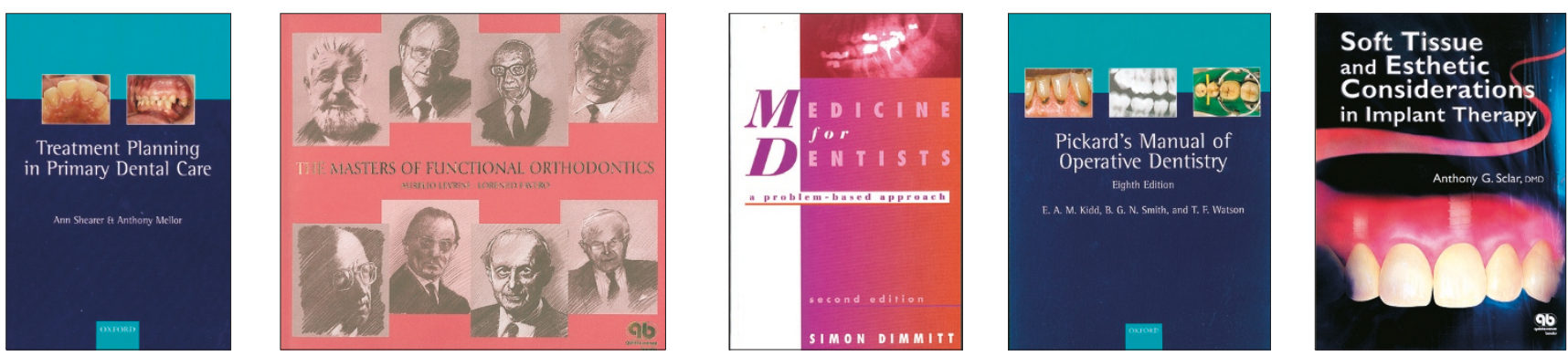

pregnant patient and drug interactions. The glossary is long enough to be quite comprehensive and informative and is a worthwhile feature of the book.

Overall, this book deserves a place for reference with any general dental practitioner, as well as the junior hospital dental surgeon.

\section{A. Banerjee}

\section{Pickard's Manual of Operative Dentistry}

E. A. M. Kidd, B. G. N. Smith and T. F. Watson

Oxford: Oxford University Press, 2003

price €35, pp209

ISBN 0198509286

Being asked to review Pickard's Manual of Operative Dentistry was like being reunited with a good old friend that I had not seen for a few years. During my undergraduate years this book was the standard text for operative dentistry, as I am sure it was/is in many other dental schools. It is now in its eighth edition, the first being published some 41 years ago.

The authors clearly state that the intention is that this book contains the material a student needs to know about operative dentistry (except endodontic and periodontal treatment) up to the point that crowns become necessary. Without a shadow of doubt I feel that this book fulfils this role excellently. It is full of clear, concise and informative text, and where required these are backed up by quality photographs and illustrations. It is divided into three well thought out parts; the first is on diseases, disorders, diagnosis, decisions and designs, the second on treatment techniques and the third on monitoring and maintenance.

The eighth edition sees a whole new chapter placed to provide information to the rapidly expanding field of bonding to tooth tissue; this chapter is indeed justified and provides a good overview of current knowledge and techniques in this area.

In doing a book review you feel almost obliged to find faults with a book, as a complete compliment to the authors I can find nothing negative to say.

Pickard's Manual of Operative Dentistry has been and in my opinion still is the authoritative text on simple operative dentistry and should find a place on the shelves of all undergraduate dental students, student hygiene/therapists and student dental nurses. I also feel that this book can have considerable value to new postgraduates involved with any aspect of operative dentistry as a simple refresher text.

C. Tredwin

\section{Soft Tissue and Esthetic Considerations in Implant Therapy}

\author{
A. G. Sclar \\ Surrey: Quintessence, 2003 \\ price $\mathrm{E} 176$, pp288 \\ ISBN 0867153547
}

This book presents surgical techniques to manage peri-implant soft tissues. The text is 280 pages and lavishly illustrated with intraoperative clinical colour photographs of individual problem cases which the author has treated in a step by step fashion. It targets both novice and expert implantologists and contains practical guidelines as well as detailed information necessary for comprehensive surgical management of relevant clinical problems encountered in practice.

The books starts with a discussion of the rational and biological basis for creating a stable peri-implant environment. This section addresses the concept of osseointegration and the importance of peri-implant soft tissues representing an introduction to the text but being basically an overview of information well known to implantologists. A systematic approach to patient evaluation of the various adverse clinical conditions that may affect or compromise implant treatment then follows. After assessment of the clinical situation, specific surgical maneuvers are presented for the management of each. From there, a classification system for alveolar ridge defects specific to implant therapy is defined. Each defect is subsequently correlated with appropriate treatment options later in the book.

Surgical instrumentation, optimal flap designs, soft tissue considerations, guidelines for surgical maneuvers, and case types are presented in detail. Indications for use of periodontal soft tissue grafting and its techniques are provided, with guidelines for patient care. Most of these are useful, time-tested, techniques many of which I use myself. Techniques for augmenting tissue around implants and natural teeth, as well as large volume hard tissue grafting procedures for extensive defects of the maxilla are also presented.

The final section of the book presents a comprehensive approach to implant therapy combining both prosthetic and surgical considerations to enhance outcomes such as the use of custom healing abutments, laser soft tissue sculpting and resurfacing, and platelet rich plasma. Finally, a conceptual framework for esthetic implant site development is presented to give the implant surgeon an understanding of the sequence and timing of procedures. In addition, the appendix has treatment algorithms that help the reader navigate the challenges of treatment planning for individual cases in an abbreviated, easyto-follow, fashion.

The many clinical cases presented throughout the book can be used as a reference for the implant surgeon treating similar cases. The author has compiled documented cases from his practice to demonstrate the techniques and convey his experience to readers. This information can help clinicians master techniques that will benefit their patients.

M. Motamedi 